\title{
Artículo Especial: Obras maestras del arte universal y la medicina: “La vida es sueño" de Calderón de La Barca (1600-1681)
}

\author{
Universal Art Masterpieces and medicine: "Life is dream", by Calderón de la Barca (1600-1681)
}

Carlos Musso*

\begin{abstract}
Argumento
El rey de Polonia, Basilio, había encerrado a su hijo Segismundo en una torre desde su nacimiento porque un oráculo le había predicho que sería un rey despótico. Encerrado en su celda, e ignorante de la razón de su cautiverio, el único contacto que Segismundo tenía con el mundo era un vasallo llamado Clotaldo, a quien se le había encomendado su cuidado y educación. Un día, una mujer llamada Rosaura entabló por azar conversación con Segismundo. El rey, enterado de lo sucedido, decidió hacerle una prueba a su hijo: luego de drogarlo, haría que al despertar creyese que era el rey de Polonia y evaluaría así su actitud como soberano. De ser la de un hombre justo, lo confirmaría en el trono, pero de comportarse como un tirano, volvería a drogarlo para luego encerrarlo y hacerle creer que los días de su reinado habían sido un mero sueño. A poco tiempo de despertar, Segismundo se comportó cruelmente. Basilio decidió entonces regresarlo a su prisión. Sin embargo el pueblo de Polonia, al enterarse que poseía un príncipe heredero, organizó una revuelta y lo liberó. Segismundo entonces armó un ejército y derrotó a su padre. Luego el príncipe, recapacitando sobre su pasada conducta, adoptó una actitud conciliadora frente a Basilio, quien lo legitimó como el nuevo rey.
\end{abstract}

Las ideas directrices del texto se representan en los fragmentos seleccionados en el cuadro 1.

Cuadro 1: ideas directrices del texto.

$\begin{array}{lll}\text { El lado oscuro de la naturaleza humana } & \text { con cuya fiereza dijo: } & \text { y teniendo yo más alma, } \\ \text { Llegó de su parto el día, } & \text { hombre soy, pues que ya empiezo } & \text { tengo menos libertad? } \\ \text { y los presagios cumplidos } & \text { a pagar mal beneficios. } \\ \text { nació en horóscopo tal, } & \text { El derecho natural del hombre } & \text { Lo ilusorio de las categorías humanas } \\ \text { que el sol, en su sangre tinto, } & \text { a la libertad } & \text { ¿Qué es la vida? Un frenes. } \\ \text { entraba sañudamente } & \text { Nace el ave, y con las galas } & \text { ¿Qué es la vida? Una ilusión, } \\ \text { con la luna en desafío } & \text { que le dan belleza suma, } & \text { una sombra, una ficción, } \\ \text { nació Segismundo, dando } & \text { apenas es flor de pluma, } & \text { y el mayor bien es pequeño; } \\ \text { de su condición indicios, } & 0 \text { ramillete con alas } & \text { que toda la vida es sueño, } \\ \text { pues dio muerte a su madre, } & \text { y los sueños, sueños son. }\end{array}$

\section{Análisis de las ideas directrices}

El conocimiento de la naturaleza humana es fundamental para un adecuado ejercicio de la labor médica asistencial desde el momento que dicha naturaleza se ve directamente involucrada en la interacción del médico con sus pacientes y con sus colegas. Precisamente los tres tópicos principales de esta obra: la sombra, la libertad y lo ilusorio de la realidad, tratan aspectos fundamentales de la misma:

La sombra es el nombre con el cual Jung designó al lado oscuro del hombre, representado por los aspectos más arcaicos de la especie, como la agresividad. Sin embargo, de la sombra provienen también elementos positivos tales como la fuerza instintiva, la vitalidad y la capacidad creadora. Es por ello que su represión desmedida se consigue siempre a expensas de un menoscabo de aquellas facultades. El conflicto entre la sombra y el ego se expresa por medio de una fuerte represión ejercida por éste sobre la sombra la cual queda circunscripta al inconsciente desde donde regresa bajo la forma de reacciones violentas, o sentimientos negativos proyectados sobre otros. La salida ideal de este conflicto consiste en la asimilación de la sombra, en su domesticación, y el primer paso en ese sentido consiste en reconocer su presencia y aceptarla. Hallaremos nuestra sombra en nuestro humor, en nuestros actos fallidos, y en aquellas situaciones ante las cuales reaccionemos desmedidamente tanto a favor como en contra, así como también en los defectos o virtudes que detectamos con facilidad en los otros y que sin embargo creemos que jamás seremos capaces de poseer, ya que en estos casos el otro funciona como una suerte de espejo proyectivo. Dado que el encuentro con la sombra no es casual ni puede ser impuesto, sino que por el contrario debe ser expresamente buscado, resulta entonces indispensable para la concreción de este proceso el ejercicio del libre albedrío. La temática de la sombra la hallamos en muchas otras producciones de la cultura occidental tales como el mito del minotauro, El extraño caso del Dr Jekyll y Mr Hyde (Stevenson) o La naranja mecánica (Burguess). Pero Calderón va por más cuando incursiona en el tópico que le da título a su obra: La vida es sueño. Hay aquí una clara alusión a la alegoría de la caverna de Sócrates, en la cual éste compara a la interpretación humana del mundo con la situación en la que se encontrarían un grupo de esclavos encadenados desde su nacimiento en el interior de una oscura caverna. Desde ésta sólo pueden percibir las sombras de las cosas del mundo exterior, sombras a las que interpretan como las cosas reales del mundo. Si alguno de ellos pudiera alcanzar el exterior comprendería la diferencia entre las cosas y sus sombras. Las cosas del mundo son categorías linguísticas, meros juegos del lenguaje, ya que en el mundo real no hay cosas sino hechos; por ejemplo donde interpretamos que la sombra de Segismundo lo impulsa a asesinar, en realidad alguien muere por su causa. No hay nada malo en los sueños (ficciones lingüísticas) sino que lo malo son los sueños que se creen o aquellos que no se creen sueños, o bien expresado en términos de la alegoría la caverna sería el lenguaje, las sombras visualizadas las categorías lingüísticas y la fuga de la caverna un imposible.

\section{Conclusión}

La lectura de "la vida es sueño" de Calderón de la Barca representa una excelente oportunidad para comprender aspectos esenciales de la naturaleza humana, tales como su lado oscuro, su sed de libertad y lo arbitrario de sus interpretaciones.

\section{Bibliografía recomendada}

- Burguess A. La naranja mecánica. Madrid. Editorial Nacional. 2002

- Calderón de la Barca P. La vida es sueño. Kapeluz. Buenos Aires. 1965

- Díez Borque J, Pedraza Jiménez F, Arellano I, García Cárcel R, García Lorenzo L. Calderón de la Barca: Las mil caras del Barroco. En Solar D (Ed). La aventura de la Historia. 2000; 16: 37- 59 